\title{
Thermal Preconditioning May Prevent Tendon Adhesion by Up-Regulating VTP7 in Rats
}

\author{
Yang Tan ${ }^{a}$ Qin-Fen Wu ${ }^{b}$ Qiang Wu ${ }^{a}$ Xin-Ti Tan ${ }^{c}$ Liao-Bin Chen ${ }^{a}$
}

${ }^{a}$ Department of Orthopaedic Surgery, Zhongnan Hospital of Wuhan Universi the Affiliated Hospital of Hubei Provincial Government, 'Departme fHistolog

bartment of Surgery, Basic Medical School, Wuhan University, Wuhan China

\section{Key Words}

Thermal preconditioning $\cdot$ Heat shock protein $\quad$ RNA and ein expressions - Tendon adhesion • Rat model • Tendon surgery

\section{Abstract}

Background/Aims: The study aims on tendon adhesion by regulating $\mathrm{t}$ models. Methods: Sixty mal thermal preconditioning and 15 rats were sacrificed in erchip and evaluated. Biomech gliding distance of tend structure of the tendons chain reaction growth factor (F' cell adhesi $n$ mo ul correlatim ralys
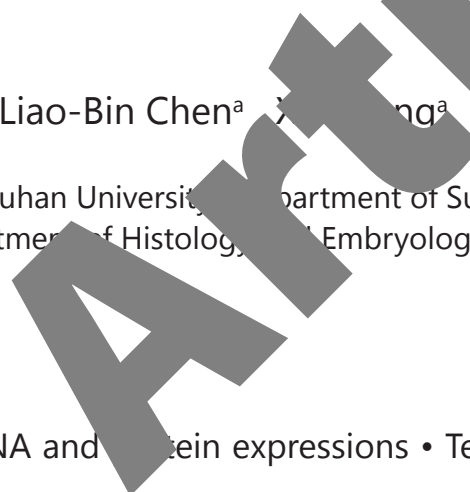
tendon sion. Kesults: At the $4^{\text {th }}$ week after surgery, we found no differences in the aa $n$ scores or mRNA and protein expressions of HSP72 between the thermal dition,, and control groups. However, after the $8^{\text {th }}$ week after surgery, the thermal prec ing group had a lower tendon adhesion score and higher mRNA and protein ress. is of HSP72 than the control group. During the same period, we found longer ding distance and higher expression levels of FGF-2, FGFR-1, $\beta$-catenin, Tenomodulin a. scleraxis, but lower EPCAM expression in the thermal preconditioning group. Pearson relation analysis indicated that HSP72 mRNA and protein expression levels were negatively correlated with tendon adhesion. Conclusions: These findings provide evidence that thermal preconditioning may alleviate tendon adhesions via upregulation of HSP72 expression.

Y. Tan and Q. Wu contributed equally to this study. 


\section{Cellular Physiology \begin{tabular}{l|l|l} 
and Biochemistry $\begin{array}{l}\text { DOI:1159/000479403 } \\
\text { Published online: July 24, } 2017\end{array}$ & $\begin{array}{l}\text { @ } 2017 \text { The Author(s). Published by S. Karger AG, Basel } \\
\text { www.karger.com/cpb }\end{array}$ \\
\hline
\end{tabular} \\ Tan et al.: Thermal Preconditioning Increases HSP72 to Prevent Tendon Adhesions}

\section{Introduction}

Tendon laceration is a common physical injury that is often caused by accidental trauma. The restoration of its full function following injury depends highly on timely, surgical treatment [1]. During the treatment process, tendon adhesion is necessary for lo of restoring function. However, excessive tendon adhesion may negatively affect the glidin function of the tendons, which is a major clinical complication following tendon surgical treatment [2]. Repaired tendons may develop complications, such as progressive fibro which results in cause adhesion formation and leads to a reduced range of motion Previous work has investigated the different processes involved in tendon aling, as inflammation, proliferation, collagen synthesis, vascularization, and apoptos difficult to prevent postoperative adhesion in tendon lacerations [1]. Adb ir pi includes postoperative treatment strategies and pharmacological in adhesive agents, such as hyaluronic acid, and anti-inflammatory drugs $1 *$ tions. been administered with reduced adhesion [5]. A study reported that egula ta heat shock protein 72 (HSP72) by heat and mechanical stress in humar blasts involves a nuclear translocation mechanism [6].

HSP72 is a stress-inducible protein member of the $h$ rotein family. HSP70 are an important component of the cell's machinery in pro to at help protect the cell during stress conditions. HSP72 functions with other $m$ ar a perones to mediate protein folding and stabilize pre-existing pr ins against regation [7]. Additionally, HSP72 also a wide variety of roles in an impo. role in in ellular protein transport, cytoskeletal architecture, mutation masking, intro $r$ redox nomeostasis and protection against spontaneous or induced programmed de ?. HSP72 has been reported to be synthesized as a cytoprotective response to $\mathrm{c}$ ar $\mathrm{s}$, and the up-regulation of HSP72 by heat and mechanical stress is a res. in human fibroblasts that involves its nuclear translocation [6]. Further ac oblas growth factor 2 (FGF-2) was found to accelerate the initial tendon-to-bone $\mathrm{e}^{\mathrm{I}} \mathrm{g}$, and its counterpart receptor, fibroblast growth factor receptor-1 (P altifunctional role in bone formation and callus remodeling $[9,10]$. A vus stuny reported that $\beta$-catenin might be involved in bone healing after fractur esp vith respect to chondrogenesis and endochondral ossification [11]. Hiraga 1. demo ated that epithelial cell adhesion molecule (EPCAM) may play an important in ce" adhesion [12]. Additionally, EPCAM expression is related to proliferative activity a $s$ in neoplastic transformation; also, regulation of EPCAM expression can ell proliferation, migration and invasion by increasing E-cadherin mediated cell $-c$ sion [13]. In 2002, it was shown that thermal preconditioning prevents $p$ iten of ahesions and inflammation in a rabbit model [14]. As an existing study $\mathrm{s}^{\mathrm{d}} \mathrm{d}$ th $\mathrm{cmal}$ preconditioning could prevent a disuse-induced fiber type t'ansfor $n$ by inducing HSP72 [15], we hypothesized that thermal preconditioning also ate tendon adhesions by inducing HSP72. In the present study, we aimed tigate re effects of thermal preconditioning on tendon adhesion and its correlation as well as the role of the expressions of FGF-2, FGFR-1, $\beta$-catenin, Tenomodulin,

\section{raxis and EPCAM in tendon tissues.}

\section{Methods and Materials}

\section{Ethics statement}

All animals were reared and treated in strict accordance with the US Guidelines for the Management and Use of Laboratory Animals [16]. All procedures performed in the study have received the approval of the Laboratory Animal Ethics Committee in Zhongnan Hospital of Wuhan University. 


\section{Cellular Physiology Cell Physiol Biochem 2017;42:1623-1634 \begin{tabular}{l|l} 
DOI: 10.1159/000479403 & Ond Biochemistry 2017 The Author(s). Published by S. Karger AG, Basel \\
Published online: July 24, 2017 & $\begin{array}{l}\text { www.karger.com/cpb } \\
\text { and }\end{array}$
\end{tabular} \\ Tan et al.: Thermal Preconditioning Increases HSP72 to Prevent Tendon Adhesions}

were kept in conditions of $23 \sim 25^{\circ} \mathrm{C}$ with $45-60 \%$ humidity for one week. All 60 rats were randomly divided into the thermal preconditioning group and control group (with no thermal preconditioning). Each group consisted of 30 rats, half of which were kept for the testing on the $4^{\text {th }}$ and $8^{\text {th }}$ weeks after surgery. The rats in both groups were anesthetized with an intraperitoneal injection of $1 \%$ pentobarbital sodium $(45$ $\mathrm{mg} / \mathrm{kg}$ ). Rats belonging to the thermal preconditioning group were maintained in a $45^{\circ} \mathrm{C}$ incubator un their rectal temperature reached $41.5 \pm 0.5^{\circ} \mathrm{C}$. This was detected by a clinical thermometer for rectal us then, they sustained the temperature for $15 \mathrm{~min}$. The rats in the control group did not receive any thermal preconditioning. All rats recovered for $24 \mathrm{~h}$ at room temperature. After their resting period, none of the died or showed signs of lethargy or fatigue.

\section{Tendon surgery and tendon adhesion evaluation}

Twenty-four hours after thermal preconditioning, the rats from both groups we vith an intraperitoneal injection of $2 \%$ pentobarbital sodium $(25 \mathrm{mg} / \mathrm{kg})$ and then fixea ontally operating table. The rats' left hind limb was then shaved and disinfected with iod 'nu " " snape incision was made into the skin of the Achilles tendon to expose the thick and thin nd. Th cendon was removed first, followed by a cut made into the middle part of thick Achili on. Non-destructive stitching was applied to tie the two ends of the thick and thin Achilles ans and sh unds. The incision was covered with sterile gauze, and the animals could recover. D week surgery, all rats wounds healed well without inflammation, infection or death, and ts rats at the $4^{\text {th }}$ week after surgery in both groups were sacrificed. The entire Achilles tendon co rats for biomechanical testing. The same procedure w? ne to remain 5 rats during the $8^{\text {th }}$ week after surgery. The remaining 15 rats in both groups were sac. Next, the e. Achilles tendon complex was removed at the $4^{\text {th }}$ and $8^{\text {th }}$ weeks after surgery for biomer. testing. At the same time, the double-blind method was used to detect postoperative tendon adhe ana ngliding function. The tendon adhesion was evaluated according to the following scoring met r17]: nits, no adhesion and the tendon glides freely without damage; 1 to 2 points, mild adh - ertus adhering to the surrounding tissues on the tendons and tendon gliding is mild all 3 to 4 points, moderate adhesion with distributed lacertus adhesion to the surrounding tissue to ns and significantly limited tendon gliding; and 5 to 6 points, many lacertus adhesi tissues, difficulty separating the tendons and from
surrounding tissues and no glidin

Quantitative real-time

Total RNA was extract

Gene Technology Co. $-\mathrm{I}+\mathrm{d}$,

Bioer Technology

instructions usi

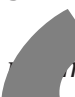
merase om 0.1 of rat tendon tissue using an RNA extraction kit (Beijing Tian Enze a). The reverse transcription kit was purchased from Hangzhou (Hairgurou, China). qRT-PCR was conducted according to the manufacturer's Biosystems® 7500 PCR System (Applied Biosystems, Inc., CA, USA). The Table 1. imer ces used for c T-PCR. qRT-PCR, quantitative ne po. se chain reaction; reat sho.ck protein 72; FGF-2,

Jlast growth factor receptor-1; EPJast growth factor receptor-1; EP-
pithelial cell adhesion molecule APDH, glyceraldehyde phosphate ehydrogenase

\begin{tabular}{lll}
\hline Gene & Direction & Sequence $\left(5^{\prime}-3^{\prime}\right)$ \\
\hline HSP72 & Forward & GGCTGACAAGAAGAAGGTGCT \\
& Reverse & CCTCTAATCCACCTCCTCGAT \\
FGF-2 & Forward & CTGGCTATGAAGGAAGATGGA \\
& Reverse & TGCCCAGTTCGTTTCAGTG \\
FGFR-1 & Forward & CTTGCCGTATGTCCAGATCC \\
& Reverse & CCTTACACACATACTCCCGC \\
3-catenin & Forward & TTGAAAATCCAGCGTGGACA \\
& Reverse & TCGAGTCATTGCATACTGTC \\
EPCAM & Forward & CGCAGCTCAGGAAGAATGTG \\
& Reverse & TGAAGTACACTGGCATTGACG \\
Tenomodulin & Forward & GTGGTCCCACAAGTGAAGGT \\
& Reverse & GTCTTCCTCGCTTGCTTGTC \\
Scleraxis & Forward & AACACGGCCTTCACTGCGCTG \\
& Reverse & CAGTAGCACGTTGCCCAGGTG \\
GAPDH & Forward & GTCGGTGTGAACGGATTT \\
& Reverse & ACTCCACGACGTACTCAGC \\
\hline
\end{tabular}




\section{Cellular Physiology Cell Physiol Biochem 2017;42:1623-1634 \begin{tabular}{l|l|l} 
and Biochemistry 10.1159/000479403 & $\begin{array}{l}\text { D } 2017 \text { The Author(s). Published by S. Karger AG, Basel } \\
\text { www.karger.com/cpb }\end{array}$
\end{tabular} \\ Tan et al.: Thermal Preconditioning Increases HSP72 to Prevent Tendon Adhesions}

primer sequences used for qRT-PCR are shown in Table 1. The PCR kit was purchased from Bio-Rad Inc. (Hercules, CA, USA). The PCR reaction procedures were performed as follows: $94^{\circ} \mathrm{C}$ pre-denaturation for 5 minutes, $94^{\circ} \mathrm{C}$ denaturation for 30 seconds, $58^{\circ} \mathrm{C}$ annealing for 30 seconds, and $72^{\circ} \mathrm{C}$ extension for 1 minutes. The denaturation - annealing - extension procedure was performed for 40 cycles. Differences in the mRNA expression between the thermal preconditioning and control groups were analyzed by the $2^{-4}$ method. The threshold cycle (CT) values of each reaction tube were obtained after the reaction, representin the number of amplification cycles when the real-time fluorescence intensity of the reaction reached the set threshold value. Multiple proportions for the relationship of the target gene expressions between thermal preconditioning and control groups were revealed by the $2^{-\Delta \Delta \mathrm{Ct}}$ method, and the formula was was as follows: $\Delta \Delta \mathrm{CT}=\Delta \mathrm{Ct}$ thermal preconditioning group $-\Delta \mathrm{Ct}$ control group $\left(\Delta \mathrm{Ct}=\mathrm{C}_{\mathrm{tHSP72}}-\mathrm{C}_{\mathrm{tGAPDH}}\right)[12]$.

\section{Western blotting}

The rat tendon tissue $(0.1 \mathrm{~g})$ was mechanically broken down and added to 0.5 (PBS) solution (1.9 mmol potassium dihydrogen phosphate, $8.1 \mathrm{mmol}$ potassium hyd mmol sodium chloride, $\mathrm{pH}$ 7.4). The cell suspension was subject to an ultrasonic di, Biological Technology Co., LTD., Ningbo, China) to disrupt the cells for a tota. second pulse with a 1-second inter-pulse interval). The samples were rifuged at $\quad \mathrm{g}$ for 10 minutes to remove the cellular debris. The total protein concentration of using the Bradford method. The results of the Bradford assay wer ed o the concentration of the protein samples. The proteins were then separated by $10 \%$ so des, sulfate-polyacrylamide gel electrophoresis (SDS-PAGE). Separated proteins he polyacryla gel were transferred onto a polyvinylidene fluoride (PVDF) membrane through a ry Blotter $($ Rad, Laboratories, Hercules, CA, USA). The PVDF membrane was first soaked in meth. 15 seconds; then, the polyacrylamide gel and PVDF membrane were soaked in buffer $(25 \mathrm{mmo} \quad 5,1$, ol glycine and $20 \%(\mathrm{v} / \mathrm{v})$ methanol) for $10 \mathrm{~min}$ at $17 \mathrm{~V}$ for $30 \mathrm{~min}$. The transferred PVDF men es $\mathrm{W}$ locked at room temperature for 2 hour in $6 \%(\mathrm{~m} / \mathrm{v})$ skim milk powder (in PBS solution ${ }^{2}$ t. d for three times, three minutes each with a PBST buffer solution [PBS solution with a $10.1 \%(\mathrm{w} / \mathrm{v})$ Tween - 20]. Samples were incubated at room temperature for 1 hour with rabbit $\beta$-catenin, Tenomodulin, scleraxi C Lhongshan Golden Bridge Biotechnology Co., LTD., Beijing, China), which was followe ashing wner PBST buffer five times three minutes each time. Next, the samples were incubated at onn re for 1 hour with a horseradish peroxidase (HRP) labeled sheep anti-rabbit IgG (Beijin ongshai en Bridge Biotechnology Co., LTD., Beijing, China), which was followed by washing with $\mathrm{P}$ buffer five times for 3 min each time. The HRP substrates (Bio - Rad) were used to color the target nrote

Image - Pro 7 as uscu lo detect the gray value of the target strip area in the Western blotting results. The rati of this prote

ie wh don complex was removed to determine the extent of its function by a mechanical test. le Achı, s tendon was removed from the heel bone to the junction of muscle and tendon and fixed ical tester (Bang Instrument Co., LTD., Suzhou, China). The tendon was firmly held, and the

on hraning place placed in the center of the fixture. A $1 \mathrm{~N}$ power was loaded and set prior to testing. ne ndon was maintained with the appropriate tension, and the initial length was measured. The tendon irst stretched $0.5 \mathrm{~mm}$ at the speed of $0.5 \mathrm{~mm} / \mathrm{s}$ three times for the pre-processing. The tendon was ontinuously loaded at a speed of $1 \mathrm{~cm} / \mathrm{min}$ until the tendon ruptured. The maximum tensile strength and gliding distance at the point of reaching the maximum tensile strength of the tendon were recorded for data processing.

\section{Hematoxylin-eosin (HE) staining}

An automatic embedding machine LEICA EG 1160 was used for paraffin embedding and a LEICA RM 2235 rotary microtome was used to slice the tissues into a thickness of $4 \mu \mathrm{m}$. The tissue slices were heated at $60^{\circ} \mathrm{C}$ until the wax dissolved; then, they were immersed in xylene twice for $5 \mathrm{~min}$ each time. Tissue slices were then immersed in $100 \%$ alcohol twice, $95 \%$ alcohol twice, $90 \%$ alcohol twice, $80 \%$ alcohol twice, and

\section{KARGER}




\section{Cellular Physiology Cell Physiol Biochem 2017;42:1623-1634 \begin{tabular}{l|l|l} 
and Biochemistry $10.1159 / 000479403$ & $\begin{array}{l}\text { DO } 2017 \text { The Author(s). Published by S. Karger AG, Basel } \\
\text { www.karger.com/cpb }\end{array}$
\end{tabular} \\ Tan et al.: Thermal Preconditioning Increases HSP72 to Prevent Tendon Adhesions}

washed with running water twice, one minute each time Slices were immersed in a Harris hematoxylin liquid for 10 minutes before being flushed with tap water for $1 \mathrm{~min}$, immersed in $1 \%$ hydrochloric acid alcohol for $30 \mathrm{~s}$ for differentiation, and flushed with running water for $15 \mathrm{~min}$ to turn the slices blue. Next, the slices were immersed in 1\% eosin alcohol for 3 min for coloration, in $90 \%$ alcohol for $30 \mathrm{~s}$ for differentiation, in $95 \%$ alcohol for $1 \mathrm{~min}$ for washing, and in dimethyl carbonate for $1 \mathrm{~min}$ for washing before washithree times with dimethylbenzene, each time for 2 min. Finally, neutral gum (GT21316; Huayueyan Biotechnology (Beijing) CO., LTD., Beijing, China) was used as a sealant. The morphological structure of the rats' tendons before thermal preconditioning and 4 weeks after surgery were observed under a microscope. Histological characteristics of tendon healing were observed under a light microscope. Image-Pro Plus 5.0 software, each HE stained section was evaluated at 100x microscopy fiber analysis.

\section{Masson staining}

We performed the same procedures of fixation, dehydration, embedding, secti slices were the same as for HE staining. The slices were first dewaxed with distilled Weigert hematoxylin for $5 \sim 10$ minutes. The slices were washed with water, diffe, alcohol, and rinsed with running water for several minutes. The slic re then s. solution for 5 minutes, washed with distilled water, and treated ws 5 minutes. Under the microscope, the muscle fibers appeared red an slices were directly stained with aniline blue or bright green liquid for acetic acid for 1 minute. Afterward, they were treate th $95 \%$ alcoh xylene transparent, and neutral gum sealing. Under the aniline blue) or green (with bright green liquid); the myred and the cell nuclei was seen as blueish brown. Ea the light microscope. The changes in the collagen fibe

cope, the $\mathrm{c}$

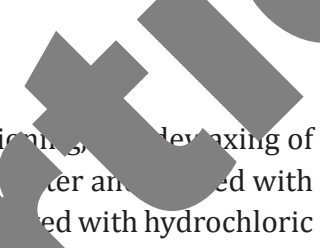
g with acid fuchsin num phate solution for rs were light red. The s, an treated with $1 \%$ glacial hydrous alcohol dehydration, en fibers appeared blue (with ep used to control the dyeing effect under tent observed with Masson staining

\section{Immunohistochemical staining}

The tissue slices were conventional peroxide for 1 hour to block endo times, 2 minutes each time.; Antiab71946), FGF-2 (1:500, ab88 $)$, ia (1:1000, ab58655) were ad were purchased from Abca. solution three times, 2 minu ab6721, Abcam Ir temperature, fol re? Beijing Zhor han en times rinse with PBS solution. 3,3'-diaminobenzidine (DAB) (ZLI-9034; to the slices and incubated overnight at $4^{\circ} \mathrm{C}$. All antibodies used c., (Ca`bridge, MA, USA). The slices were removed and washed with PBS ne. The HRP-labeled sheep anti-rabbit secondary antibody (1:500, per ser water and then treated with $3 \%$ hydrogen a vity. PBS solution was used to wash the slices three mary annodies of $\beta$-catenin (1:1000, ab16051), EPCAM (1:100, 0, ab63601), Tenomodulin (1:500, ab203676) or scleraxis (1) ed ce microscope. The coloration was terminated $y^{\prime \text { ith }}$ run ciona. nnt alcohol dehydration and sealing with neutral gum. Three visual fields of each sample domly rected for observation at $10 \times$ magnifications. Image-Pro Plus 6.0 software was used to emi-quantitative value of the mean light density of positive cells (tan particles in the cells

consuered positive). Total number of cells and number of positive cells were calculated. The ratio of sitive cell rate equals the number of positive cells divided by the number of total cells, which gave us ative expression of the target protein in the cell.

\section{Statistical analysis}

SPSS 19.0 software was used for data analysis. Data collected were expressed as a mean \pm standard deviation (SD) and tested for normality. The comparisons for significance within the measurement data were conducted using the $t$ test. The $\chi^{2}$ test was used for comparisons within the enumeration data. Spearman correlation analysis was applied for correlation analysis. The receiver operating characteristic curve (ROC curve) was used to analyze the diagnostic value of HSP72 mRNA and protein expression levels in tendon adhesion at the $8^{\text {th }}$ week after surgery. Value of $P<0.05$ was considered statistically significant.

\section{KARGER}




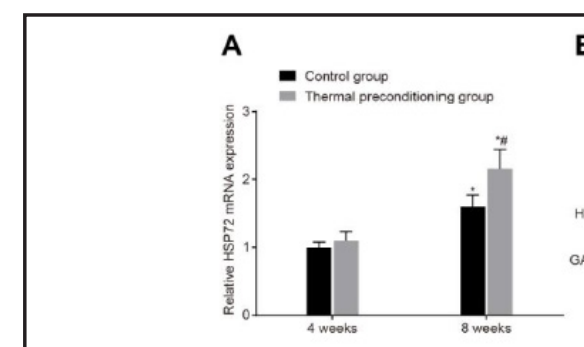

D

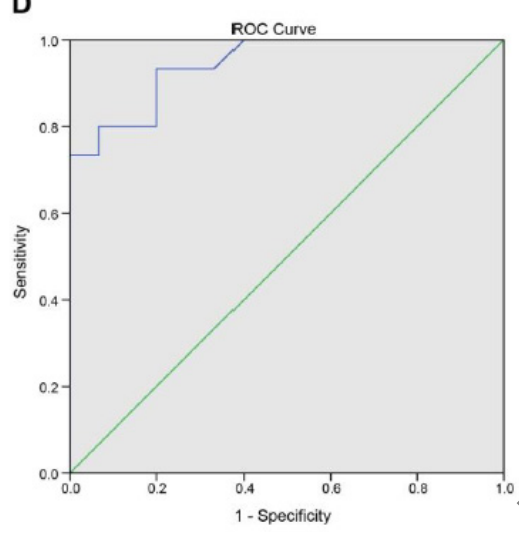

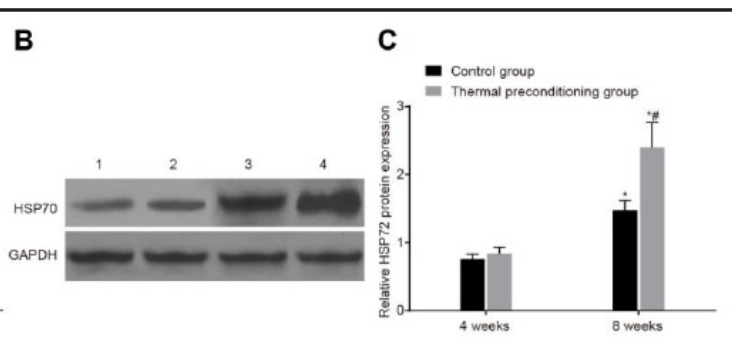

E
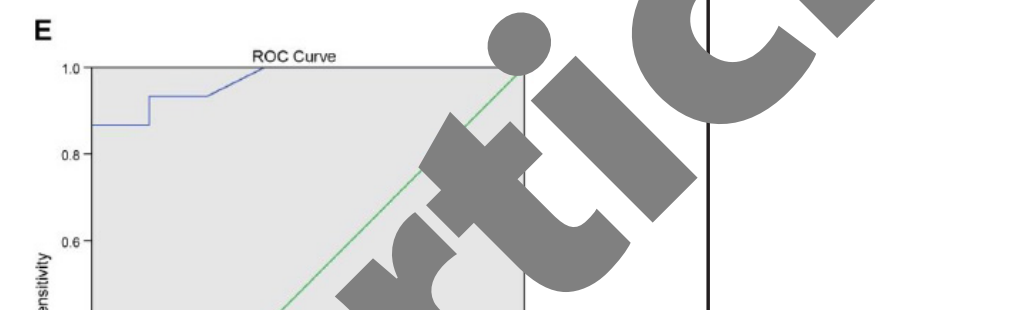

Fig. 2. Comparison of mRNA and protein expression lf and control groups $(\mathrm{n}=15)$. Note: $(\mathrm{A})$ Relative expr the control group before thermal preconditioning is a protein expression in the two groups; (C) HS value of HSP72 mRNA expression in tendor the diagnostic value of HSP72 pro ${ }^{\wedge i n}$ expr 0.05 , compared with the $4^{\text {th }}$ weel week after surgery.

Table 2. Comp ween the thern

on of the Iraximum tensile strength and sliding distance for tendons betarges. he at the $8^{\text {th }}$ week after surgery; E, ROC curve analyzing 12 don adhesion at the $8^{\text {th }}$ week after surgery; $*, P<$ $P<0.05$, compared with the control group at the $8^{\text {th }}$

72 between the thermal preconditioning n of mRNA with the mRNA expression in (B) Western blotting showing of HSP72 sion; D, ROC curve analyzing the diagnostic 

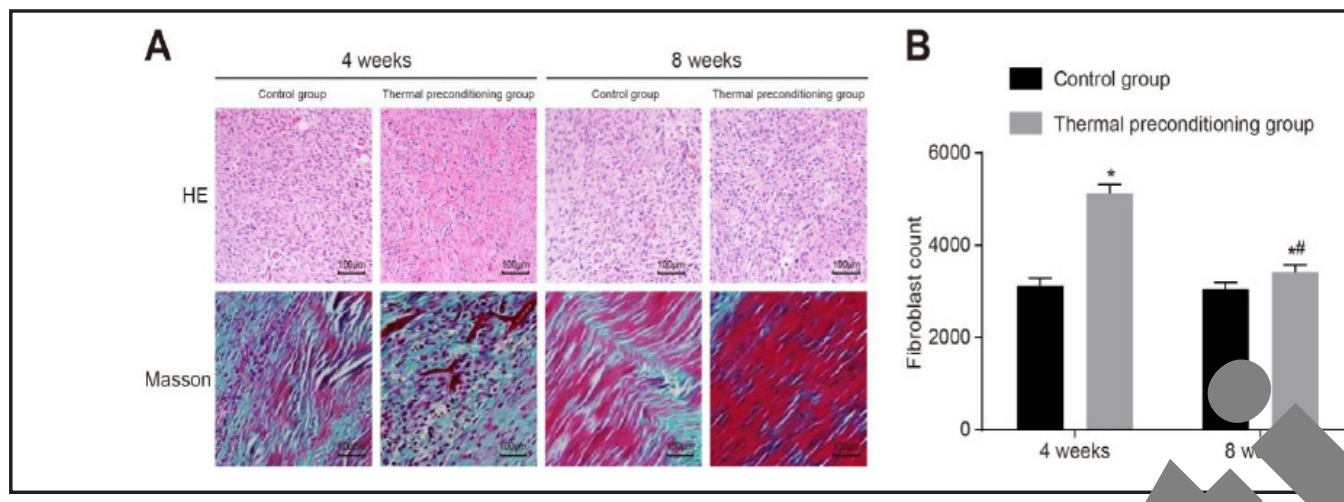

Fig. 3. Sagittal sections of the Achilles tendon after surgery detected by HE staining Note: A, Sagittal sections of the Achilles tendon after surgery detected by HE stainipo and Màson staining $(\times 100)$; B, statistics for two groups of postoperative fibroblast count $(n=1$

Fig. 4. Comparison of the expression levels of FGF-2, FGFR1 , $\beta$-catenin, Tenomodulin and scleraxis and EPCAM between the thermal preconditioning and control groups. Note: A, expressions of FGF-2, FGFR-1, $\beta$-catenin, Tenomodulin, scleraxis and EPCAM between the thermal preconditioning and control groups detected by immunohistochemical staining ( $\times 200)$; B, positive expression rates of FGF-2, FGFR-1, $\beta$-catenin, Tenomodulin, scleraxis and EPCAM betwe the thermal preconditioning control groups; C, mRNA ex sion of FGF-2, FGFR-1 B-cato Tenomodulin, scl $f$ CAM between conditionine nd $\mathrm{co}$ detected T-PC al $\mathrm{ps}$

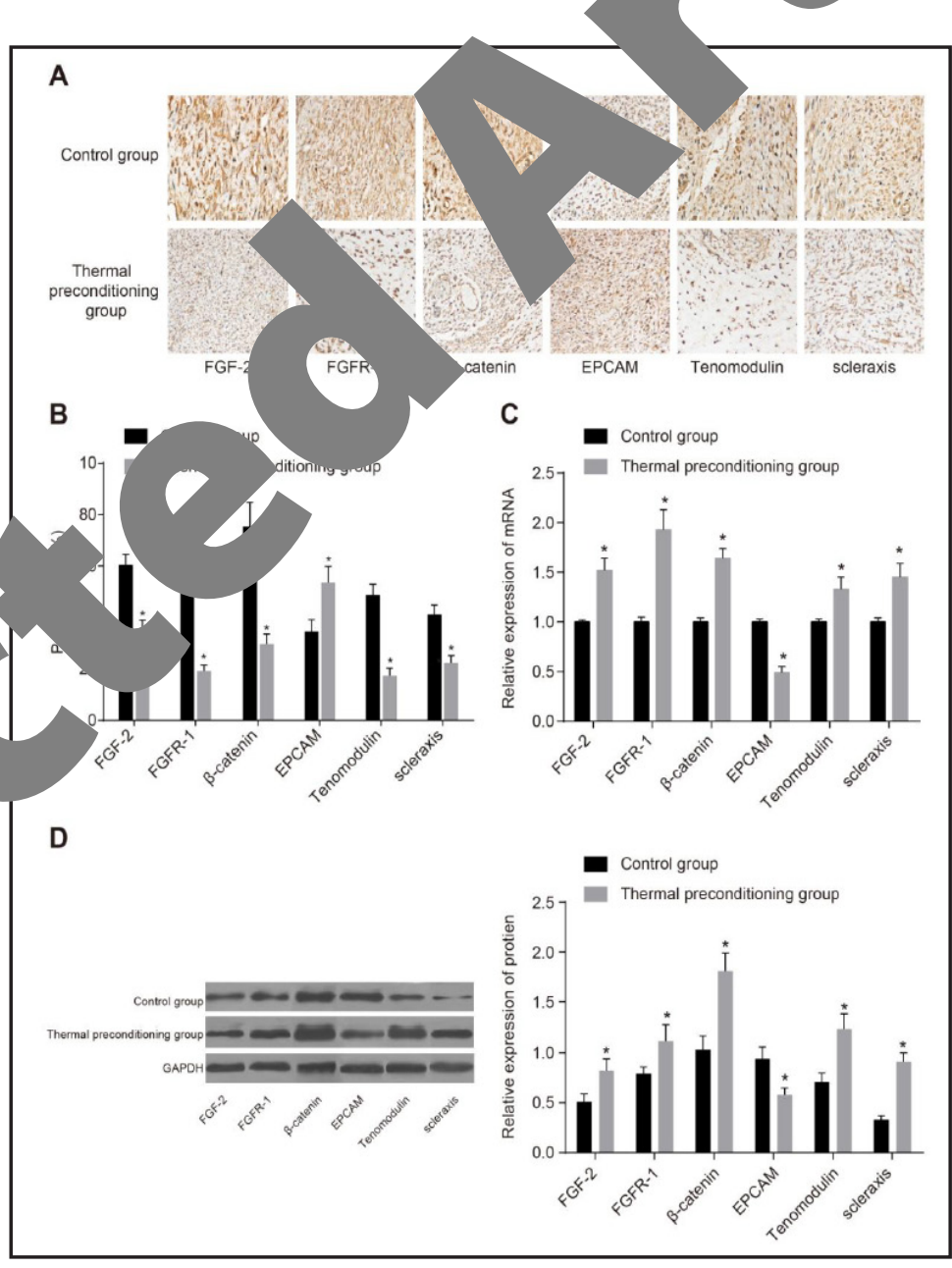
e"vressio FGF-2, FGFR-1, EPCA between the thern onditioning and rol groups detected by Wesro hlotting; * $P<0.05$ comwith the control group $=15)$.

disorderly collagen fibers, collagen bundles of different degrees and a red-green color. At the $8^{\text {th }}$ week after surgery, the thermal preconditioning group had many regularly arranged collagen fibers, collagen bundles of the same diameter, and red-dyed mature collagen fibers, while the control group had disorderly arranged collagen fibers, collagen bundles of different diameters and a mature red-green color (Fig. 3A). Analysis of fibroblast counts in each group by Imapge-Pro Plus software revealed that there was a significant delay in the fibroblast proliferation in the thermal preconditioning group (Fig. 3B).

\section{KARGER}


Fig. 5. Correlation of HSP72 mRNA and protein expression with tendon adhesion at the $8^{\text {th }}$ week after surgery. Note: A, correlation of HSP72 mRNA expression with tendon adhesion at the $8^{\text {th }}$ week after surgery; B, correlation of HSP72 protein expression with tendon adhesion at the $8^{\text {th }}$ week after surgery $(n=30)$.

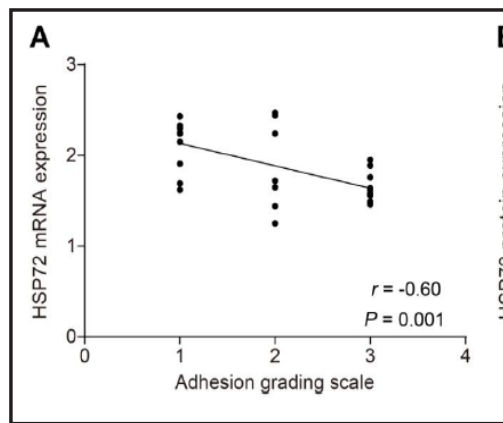

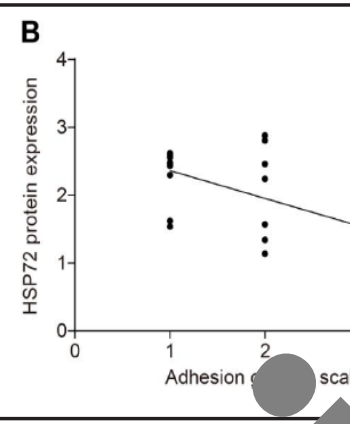

\section{(1)}

The expression levels of FGF-2, FGFR-1, $\beta$-catenin and EPCAM in the therm and control groups

We found that expression levels of FGF-2, FGFR-1, $\beta$-catenin, Tenom were higher, while EPCAM expression levels was lower than in the con (Fig. 4). Therefore, we concluded that FGF-2, FGFR-1, $\beta$-catenin, Teno lin, scleraxis and EPCAM were associated with the degree of tendon adhesic r were $r$ FGF-2, FGFR$1, \beta$-catenin, Tenomodulin and scleraxis and high for EF sicating severe tendon adhesion.

\section{Correlation of HSP72 mRNA and protein evion levels tendon adhesion}

The tendon adhesion scores with HSP72 m. nd protel spression levels for rats in the thermal preconditioning and control group $\quad{ }^{\text {th }}$ week after surgery were analyzed by Spearman correlation analysis. Results wea the HSP72 mRNA and protein expression levels were negatively correlated $v$ the see of tendon adhesion, suggesting that low HSP72 mRNA and protein expr icate serious tendon adhesion and a high tendon adhesion score (Fig. 5).

\section{Discussion}

Tendon stem cells present a high multi-diff $[18,19]$, and disordared the pathogenes; the ruptured th de while the r har a HSP72 ossio or thermal preconditioning and adhesion of tendons showed that t'ermal nditioning might increase the HSP72 mRNA and protein expression levels and ten dhesion after tendon surgery. Thermal preconditioning is an easily applied treatn. ant method to prevent the adhesion of tendons.

sent study showed that although there was no difference in mRNA and protein ression levels of HSP72 between both groups at the $4^{\text {th }}$ week after surgery. We detected ted levels of expression later on during the $8^{\text {th }}$ week after surgery. Interestingly, the mal preconditioning group presented with a significantly higher expression levels of 1 P 72 mRNA and protein than the control group. In the meantime, the findings indicated that the HSP72 mRNA and protein expression levels were negatively related to tendon adhesion and the tendon adhesion score. We speculate that the up-regulated in expression of HSP72 was observed in the $4^{\text {th }}$ week after surgery in both groups was due to the surgical procedure itself which has been previously reported to increase HSP72 in some instances [22]. Additionally, we also found that the thermal precondition group showed higher expression of HSP72 in the $8^{\text {th }}$ week after the surgery than the control group, which could be supported by the statement that thermal preconditioning can activate HSP72 [23]. The production of the flexor tendon graft requires the expansion of primary cells. During tendon 
damage and collagen synthesis, the cells that have multiple fibripositors and cytoplasmic protrusions can be found in the area [4]. HSP72 is the most important member of the heatshock protein family [24]. Studies have confirmed that when body cells are subjected to stressful conditions, such as hyperpyrexia, oxidation, and mechanical damage, the increased expression of HSP72 can strengthen the tolerance of cells to damage, improve the viabil of the cells, and reduce cell necrosis or apoptosis caused by stress injury [25]. In line wit our results, many previous studies have proposed that increased HSP72 can promote tissue repair by strengthening to the ability of cells to resist stressful damage, increased degradation of abnormal proteins, and maintain the normal biological activitu of the through the enhancement of the stability of the internal structures, and havin prote effect [26-28]. Millar and Murrel et al. investigated the central role of HSPs
disease and reported that HSPs may ultimately affect tissue rescue mech pathology [28]. Barbe et al. reported that HSP72 increases in the musclo tend of rats that performed a repeated high demand reaching and grasping tas ${ }^{1}$ to Similarly to our study, Healy et al. have also reported that thermal pr nditi of the limb before flexor tendon repair decreases inflammation and adhesio mation in a rabbit model, suggesting that it has the potential to improve the al outco flexor tendon surgery [29]. Thermal preconditioning is also proved to the formation of cytoprotective HSPs [30].

Our study showed that at the $8^{\text {th }}$ week after surgery, the had a longer gliding distance and higher expr in levels o. ál p.econditioning group with lower EPCAM expression than the control g, Growth fas s, such as platelet-derived growth factor-BB (PDGF-BB), insulin-like growth $\quad 1$ (IGF-1), and basic fibroblast growth factor (bFGF), are known to promote tendon $\mathrm{h}$ ng andon cell proliferation [31]. FGF2 has been reported to accelerate the initial on-t whe remodeling and FGFR-1 plays a multifunctional role in bone formatio nodeling. $\beta$-catenin widely exists in fibroblasts and osteoblasts, and it p) porcant role in regulating the proliferation, differentiation and apoptosis of these 12 The early growth response 1 (EGR1) plays a vital role in the process of te Smad1/5/8 signaling pathw induce autophagy cell deat" nite. 3]. Aaurcionally, the cyclic mechanical stretching could play a negative role in te regulated by miR-218 [ quickened through implà interacting fact TF1) gene silencing [36]. All growth factors, including bFGF, could increase colla 1 y production, which may further reinforce the histological and biomechar pl pr of regenerative tendons [37]. EPCAM expression has been found to be ac ated Cllular differentiation. Findings show that the germinal regions in r rrmal ic crypts display increased EPCAM expression but as the cells differentiate and ce to $\quad p$ of the villi, its expression decreases [38]. The reason for the reduction in CAM e $x_{p}$ ression might be due to the reduction of adhesion between the tendon and tissues after thermal preconditioning. on-bont aing, which implying that TOB1 expression might be The $r$ rdy healing process of tendon-to-bone junctions could be don-derived stem cells (TDSCs) with transforming growth

In conclusion, our results demonstrated that thermal preconditioning could reduce in adhesion via up-regulating of HSP72 mRNA and protein expression levels following on surgery. Thermal preconditioning is an easily applied clinical treatment method to r event tendon adhesion. As of now, the precise mechanism of how thermal preconditioning is yet to be determined. Future investigation is requiring elucidating its possible association with other molecules and pathways.

\section{Acknowledgments}

This study was supported by a project of the Natural Science Foundation of Hubei Province (No. 2009CDB016). We would like to acknowledge the helpful comments that we received from our reviewers. 


\section{Cellular Physiology Cell Physiol Biochem 2017;42:1623-1634 and Biochemistry Published online: July 24, $2017 \quad \begin{aligned} & \text { DOI: 10.1159/000479403 } 2017 \text { The Author(s). Published by S. Karger AG, Basel } \\ & \text { www.karger.com/cpb }\end{aligned}$ \\ Tan et al.: Thermal Preconditioning Increases HSP72 to Prevent Tendon Adhesions}

\section{Disclosure Statement}

The authors declare no conflict of interest.

\section{References}

1 Akbari H, Rahimi AA, Ghavami Y, Mousavi SJ, Fatemi MJ: Effect of Heparin on Post-Operative Adhesion ir Flexor Tendon Surgery of the Hand. J Hand Microsurg 2015;7:244-249.

2 Dabak TK, Sertkaya O, Acar N, Donmez BO, Ustunel I: The Effect of Phospholipids (Surfacta Adhesion and Biomechanical Properties of Tendon: A Rat Achilles Tendon Repair Model. Biom 2015;2015:689314.

-3 Wong JK, Metcalfe AD, Wong R, Bush J, Platt C, Garcon A, Goldspink N, McGrouther DA, Reduction of tendon adhesions following administration of Adaprev, a hypertonic $S$ phosphate: mechanism of action studies. PLoS One 2014;9:e112672.

-4 Wong JK, Lui YH, Kapacee Z, Kadler KE, Ferguson MW, McGrouther DA: The cei adhesion formation: an old problem in a new paradigm. Am J Path 9:175:19. Meier Burgisser G, Calcagni M, Muller A, Bonavoglia E, Fessel G, 5 J: Prevention of peritendinous adhesions using an electrospun De ultrasonographic, and biomechanical study in rabbits. Biomed Res I strain and heat of human tendon fibroblasts on HSPKrettek C, Ze J Appl Phys $\mathrm{J}$ : Influence of cyclic mechanical

7 Chow AM, Steel R, Anderson RL: Hsp72 chaperone fur induced apoptosis. Cell Stress Chaperones 2009;14 Wu YF, Mao WF, Zhou YL, Wang XT, Liu PY, Tang JB:

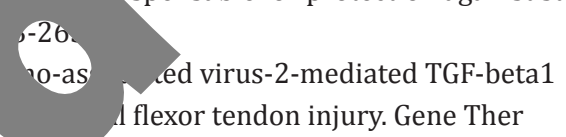
2016;23:167-175. of fibroblast growth factor- 2 supraspinatus tendon. J Shoul

10 Nakajima A, Nakajima F, St izu S, temporal gene expressic the rat. Bone 2001;29:4 ribrobla.<smiles>CC(C)(C)c1ccccc1-c1ccccc1</smiles>
flexor tendon injury. Gene Ther An Mh 1 (2) logy of flexor tendon in 1 Huang Y, Zhang X $\cap_{\mu} \mathrm{K}$, 66. ow Surg -ov9;18:391-398. oto T, Mizuta H: The effect of a local application deling in rats with acute injury and repair of the ra A, Wanaka A, Moriya H, Einhorn TA, Yamazaki M: Spatial and wth factor type I receptor (FGFR1) during fracture healing in chondrocytec elayeunacture healing in mice. J Orthop Res 2012;30:304-310.

$\checkmark 12$ Hiraga T, It N EpCAM expression in breast cancer cells is associated with enhanced bone metast forn on w, Cancer 2016;138:1698-1708.

13 Ost Chen Carian K, Mitas M, Salem M, Hannun YA, Cole DJ, Gillanders WE: EpCAM is

sed in breast cancer and is a potential target for breast cancer gene therapy. Cancer Res $504 ; 6$.

- Ihall KJ, ,CLaughlin R, Kay E, Kiely P, Bouchier-Hayes D, Murray P: Thermal preconditioning prevents hous adhesions and inflammation. Clin Orthop Relat Res 2002;258-266.

Takeua I, Fujino H, Murakami S, Kondo H, Nagatomo F, Ishihara A: Thermal preconditioning prevents siber type transformation of the unloading induced-atrophied muscle in rats. J Muscle Res Cell Motil 2009;30:145-152.

Health TNACRfbNIo: Guide for the Care and Use of Laboratory Animals. National Research Council (US) Committee for the Update of the Guide for the Care and Use of Laboratory Animals 2011; Zhao H, Guan HG, Gu J, Luo ZP, Zhang W, Chen B, Gu QL, Yang HL, Shi Q: Collagen membrane alleviates peritendinous adhesion in the rat Achilles tendon injury model. Chin Med J (Engl) 2013;126:729-733.

-18 Chen H, Ge HA, Wu GB, Cheng B, Lu Y, Jiang C: Autophagy Prevents Oxidative Stress-Induced Loss of SelfRenewal Capacity and Stemness in Human Tendon Stem Cells by Reducing ROS Accumulation. Cell Physiol Biochem 2016;39:2227-2238. 


\section{Cellular Physiology Cell Physiol Biochem 2017;42:1623-1634 \begin{tabular}{l|l} 
DOI: 10.1159/000479403 & and Biochemistry \\
Published online: July 24, 2017 & $\begin{array}{l}\text { 2017 The Author(s). Published by S. Karger AG, Basel } \\
\text { www.karger.com/cpb }\end{array}$
\end{tabular}

19 Liu X, Chen W, Zhou Y, Tang K, Zhang J: Mechanical Tension Promotes the Osteogenic Differentiation of Rat Tendon-derived Stem Cells Through the Wnt5a/Wnt5b/JNK Signaling Pathway. Cell Physiol Biochem 2015;36:517-530.

20 Liu J, Tao X, Chen L, Han W, Zhou Y, Tang K: CTGF positively regulates BMP12 induced tenogenic differentiation of tendon stem cells and signaling. Cell Physiol Biochem 2015;35:1831-1845.

21 Chen W, Tang H, Liu X, Zhou M, Zhang J, Tang K: Dickkopf1 Up-Regulation Induced by a High Concentratio of Dexamethasone Promotes Rat Tendon Stem Cells to Differentiate Into Adipocytes. Cell Physiol Biochem 2015;37:1738-1749.

22 Fleshner M, Campisi J, Amiri L, Diamond DM: Cat exposure induces both intra- and extracellular Hsp7 the role of adrenal hormones. Psychoneuroendocrinology 2004;29:1142-1152.

23 Cheng L, Smith DJ, Anderson RL, Nagley P: Modulation of cellular Hsp72 levels in undifferenti? and neuron-like SH-SY5Y cells determines resistance to staurosporine-induced apopt 2011;6:e24473.

-24 Parseghian MH, Hobson ST, Richieri RA: Targeted heat shock protein 72 for pulmon N Y Acad Sci 2016;1374:78-85.

25 Millar NL, Murrell GA: Heat shock proteins in tendinopathy: novel molecular Inflamm 2012;2012:436203.

26 Barbe MF, Gallagher S, Massicotte VS, Tytell M, Popoff SN, Barr-C repetition on musculoskeletal and neural tissue responses and se work-related musculoskeletal disorders. BMC Musculoskelet Disora

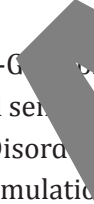
Tytell M, Barbe MF, Brown IR: Stress (heat shock) p
relationship to cell stress and damage. Adv Neurol 1. rat corneal epithelium by hyperthermia. Curr Eye Healy C, Mulhall KJ, Fitz Patrick D, Kay EW, Bouchi limb on flexor tendon healing. J Hand Surg

30 Healy C, Mulhall KJ, Nelligan M, Murray P uv Hayes D:Postoperative stiffness and adhesion formation around repaired and immobi
shock protein induction. J Sur

-31 Costa MA, Wu C, Pham BV, Cho Pham hin, enang J: Tissue engineering of flexor tendons: optimization of tenocyte p ifta $\quad$ orowth factor supplementation. Tissue Eng 2006;12:19371943.

-32 Wang PP, Zhu XF, Yang I bone formation through Res 2012;14:

-33 Tao X, Liu J en Tang K: EGR1 induces tenogenic differentiation of tendon stem cells and promo rabbi tat uff repair. Cell Physiol Biochem 2015;35:699-709.

-34 Che nen L, Biang C: Cyclic mechanical stretching induces autophagic cell death in

teno 1 asts through activation of prostaglandin E2 production. Cell Physiol Biochem 2015;36:24-33. Lo Y, $\quad$ Lu Y, Wang Y, Kou X, Lou Y, Kang Y: TOB1 Deficiency Enhances the Effect of Bone Marrowrived Mu unchymal Stem Cells on Tendon-Bone Healing in a Rat Rotator Cuff Repair Model. Cell Physiol 2016;38:319-329.

Chen L, Jiang C, Tiwari SR, Shrestha A, Xu P, Liang W, Sun Y, He S, Cheng B: TGIF1 Gene Silencing in TendonDerived Stem Cells Improves the Tendon-to-Bone Insertion Site Regeneration. Cell Physiol Biochem 2015;37:2101-2114.

Zheng L, Wang Q, Wei KH: [The influence of basic fibroblast growth factor on the adhesion characteristics of osteoblasts in rabbit]. Zhongguo Xiu Fu Chong Jian Wai Ke Za Zhi 2000;14:305-307.

Maaser K, Borlak J: A genome-wide expression analysis identifies a network of EpCAM-induced cell cycle regulators. Br J Cancer 2008;99:1635-1643. 